\title{
Radiology in Vertigo and Dizziness
}

Deepak Patkar, Girish Yevankar, Rashmi Parikh

\begin{abstract}
Objective: Vertigo may or may not be associated with hearing loss. In addition, the imaging findings are often subtle. Underdiagnosis of cause of vertigo on imaging can lead to long standing annoying symptom of vertigo.

Conclusion: This article reviews the radiologic findings of vertigo. After completing this article, the readers should have an improved ability to diagnose the common causes of vertigo, using the optimal imaging tools to achieve this goal.
\end{abstract}

Keywords: American College of Radiology, Magnetic resonance imaging, Magnetic resonance angiogram.

How to cite this article: Patkar D, Yevankar G, Parikh R. Radiology in Vertigo and Dizziness. Otorhinolaryngol Clin Int J 2012;4(2):86-92.

\section{Source of support $\mathrm{Nil}$}

Conflict of interest: None declared

\section{INTRODUCTION}

Imaging plays an important role in the diagnosis and treatment of the patients with vestibular abnormalities.

There are multiple imaging tools available for the patients with vestibular and temporal bone abnormalities viz computed tomography (CT) scan, magnetic resonance imaging (MRI) including MR angiography and digital subtraction angiography.

Communication with radiologist prior to the testing ensures that the most appropriate modality is employed for the clinical situation. ${ }^{1}$

Physicians should consider neuroimaging studies in patients with vertigo who have neurologic signs and symptoms, risk factors for cerebrovascular disease or progressive unilateral hearing loss. ${ }^{2}$

\section{Differential Diagnosis of Vertigo}

Causes

Peripheral causes ${ }^{2-8}$

- A cute labyrinthitis

- A cute vestibular neuronitis (vestibular neuritis)

- B enign positional paroxysmal vertigo (benign positional vertigo)

- Cholesteatoma

- Herpes zoster oticus (Ramsay Hunt syndrome)

- M énière's disease (M énière's syndrome, endolymphatic hydrops)

- Otosclerosis

- Perilymphatic fistula

- Central causes
- Cerebellopontine angle tumor

- Cerebrovascular disease, such as transient ischemic attack or stroke

- Migraine

- Multiple sclerosis

- Other causes

- Cervical vertigo

- Drug-induced vertigo

- Psychological

The appropriate imaging modality depends upon the associated symptoms and is guided by ACR criterion as given in Table 1 (ACR A ppropriateness Criteria)**. ${ }^{9}$

\section{Labyrinthitis}

Labyrinthitis is an inflammation of the membranous labyrinth ${ }^{10}$ and can be divided according to etiology as follows:

- Tympanogenic

- Post-traumatic

- Meningogenic

- Hematogenic

- Autoimmune

Prior to MRI, no imaging findings were described; however, now enhancement of the labyrinth on postcontrast TIWI enable the diagnosis to be made with confidence.

Regardless of etiology M RI findings of labyrinthitis is postcontrast enhancement of normally non-enhancing fluidfilled space of labyrinth.

When toxins only, then the term 'acute toxic labyrinthitis' or 'acute serous labyrinthitis' is used. MRI may be negative.

When bacteria actually enter the labyrinth, then 'acute suppurative labyrinthitis' applies, and M RI is positive.

\section{Post-traumatic}

Post-traumatic labyrinthitis is seen usually seen in the setting of temporal bone fracture with a resulting perilymphatic fistula. ${ }^{11,12}$

Precontrast T1WI are acquired to distinguish between labyrinthine, enhancement and hemorrhage. In hemorrhage, low signal intensity is replaced by high intensity due to methemoglobin. ${ }^{13}$

Image

On an axial contrast material-enhanced T1-weighted M R image, the basal turn of the cochlea demonstrates enhancement. 


\begin{tabular}{|c|c|c|c|c|c|c|}
\hline & $\begin{array}{l}\text { MRI head } \\
\text { and internal } \\
\text { auditory canal } \\
\text { without and } \\
\text { with contrast }\end{array}$ & $\begin{array}{l}\text { MRI head } \\
\text { and internal } \\
\text { auditory canal } \\
\text { without contrast }\end{array}$ & $\begin{array}{l}\text { CT temporal } \\
\text { bone without } \\
\text { contrast }\end{array}$ & $\begin{array}{l}\text { CT head } \\
\text { without } \\
\text { and with } \\
\text { contrast }\end{array}$ & $\begin{array}{l}\text { MRA head } \\
\text { with or } \\
\text { without } \\
\text { contrast }\end{array}$ & $\begin{array}{l}\text { CTA } \\
\text { head }\end{array}$ \\
\hline $\begin{array}{l}\text { Sensorineural hearing loss, } \\
\text { acute and intermittent vertigo }\end{array}$ & 8 & 7 & $6^{\dagger}$ & 3 & $\mathrm{~N} / \mathrm{A}$ & $\mathrm{N} / \mathrm{A}$ \\
\hline $\begin{array}{l}\text { Sensorineural hearing loss, } \\
\text { no vertigo }\end{array}$ & 8 & 7 & 5 & 4 & $\mathrm{~N} / \mathrm{A}$ & $\mathrm{N} / \mathrm{A}$ \\
\hline $\begin{array}{l}\text { Conductive hearing loss, rule } \\
\text { out petrous bone abnormality }\end{array}$ & 3 & $3^{\ddagger}$ & 8 & 3 & $\mathrm{~N} / \mathrm{A}$ & N/A \\
\hline $\begin{array}{l}\text { Total deafness, cochlear implant } \\
\text { candidate, surgical planning }\end{array}$ & 5 & 5 & 9 & 3 & $\mathrm{~N} / \mathrm{A}$ & $\mathrm{N} / \mathrm{A}$ \\
\hline $\begin{array}{l}\text { Fluctuating hearing loss, } \\
\text { history of meningitis or to } \\
\text { rule out congenital anomaly }\end{array}$ & 7 & 7 & 8 & 4 & $\mathrm{~N} / \mathrm{A}$ & N/A \\
\hline $\begin{array}{l}\text { Episodic vertigo, new onset } \\
\text { (hours to days) }\end{array}$ & 7 & 6 & 4 & 5 & 6 & 5 \\
\hline $\begin{array}{l}\text { Vertigo, no hearing loss, } \\
\text { normal findings on } \\
\text { neurologic examination }\end{array}$ & 8 & 7 & 5 & 4 & $\mathrm{~N} / \mathrm{A}$ & $\mathrm{N} / \mathrm{A}$ \\
\hline
\end{tabular}

Note: MRI: Magnetic resonance imaging; MRA: MR angiography; CTA: CT angiography; N/A: Not rated; *Appropriateness criteria scale from 1 to 9; 1 indicates least appropriate; ${ }^{* *}$ M ost appropriate; ${ }^{\dagger}$ For possible cholesteatoma with labyrinthine fistula; ${ }^{\ddagger} M R$ imaging is superior to $\mathrm{CT}$ for the detection of dural invasion and extradural extension

\section{Labyrinthitis Ossificans (Sclerosing Labyrinthitis)}

The most common cause of labyrinthitis ossificans ( $L O)$ is suppurative bacterial labyrinthitis following bacterial meningitis.

\section{CT Scan}

Ossification generally extends from the basal turn to apical turn. Early CT shows ill-defined haziness of labyrinth. The end stage is easily demonstrated by CT scan and is characterized by total 'whiteout' of membranous labyrinth (Fig. 1).

Differentiation of it from congenital otic dysplasia is made by maintained contour of otic capsule. Fibro-osseous replacement of cochlea is of paramount importance, when cochlear implantation is contemplated. ${ }^{14}$

\section{MRI}

High resolution, T2W 1, fast spin echo images show loss of normal hyperintensity of the fluid in the membranous labyrinth (Fig. 2).

\section{Perilymphatic Fistula}

It is an abnormal communication between the inner ear and middle ear which can cause vertigo and hearing loss.

The common sites are oval window and round window.

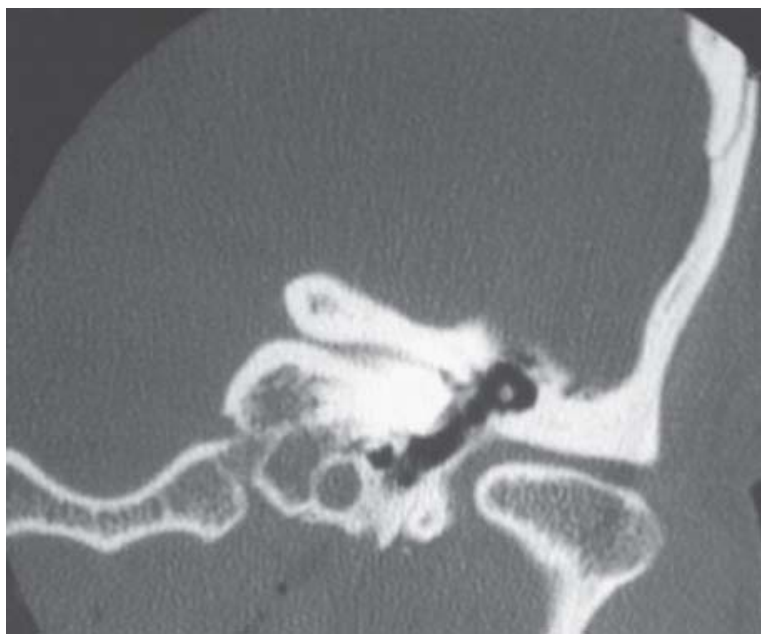

Fig. 1: CT scan showing labyrinthitis ossificans

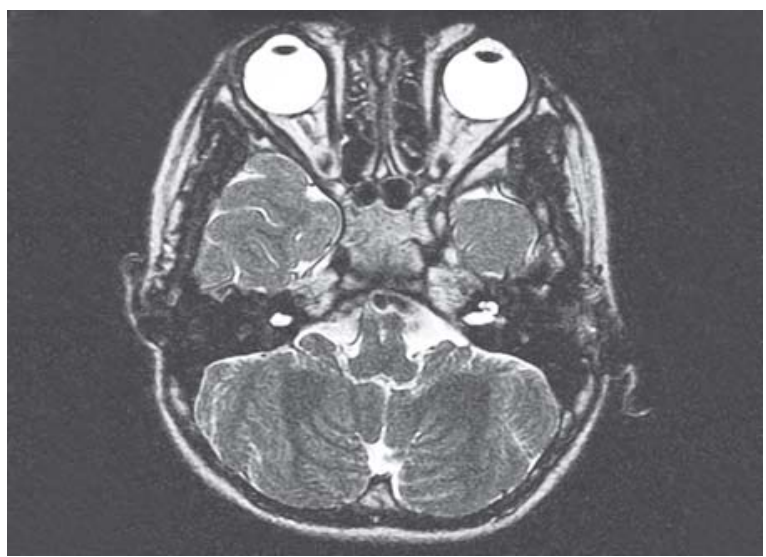

Fig. 2: Labyrinthitis ossificance with hydrops 


\section{CT Scan}

CT diagnosis is difficult and depend on fluid dynamics within the vestibule.

U nexplained dependent middle ear or mastoid fluid collection emanating from oval window should be viewed with suspicion and pneumolabyrinth is highly suggestive in this context.

Unfortunately, there may not be CT findings.

Air in the vestibule A xial image demonstrates a collection of air within the vestibule.

\section{MRI}

Diffuse T1 postcontrast enhancement of labyrinth.

Segmental enhancement is also seen at the site of perilymph fistula, presumably within the granulation tissue. $^{15}$

\section{Otosclerosis}

Otosclerosis or otospongiosis is an idiopathic infiltrative process of the petrous temporal bone that may present with tinnitus. The most common type is fenestral otosclerosis $(85 \%)$ which presents with conductive hearing loss. Cochlear or retrofenestral otosclerosis (15\%) causes additional sensorineural hearing loss. Chronic subjective tinnitus is a common feature of clinical otosclerosis, reported in $\leq 65 \%$ of patients. ${ }^{16}$

\section{CT Scan}

In early stages of otosclerosis, a radiolucent focus may be seen at the fissula ante fenestram, which is a cleft of fibrocartilaginous tissue located just anterior to the oval window. As the disease progresses, this lucency involves the margins of the oval and round windows and may even produce multiple radiolucent foci. Extension of the disease to the otic capsule may produce imaging signs of both fenestral and cochlear otosclerosis in the same patient. Cochlear otosclerosis is characterized by low-attenuation foci around the basal turn of the cochlea, though some lesions may also involve the lateral walls of the IAC and the cochlear promontory. In severe otosclerosis, a lowattenuation ring sometimes surrounds the cochlea, known as the double-ring sign. In the later healing phase, CT may show a 'heaped-up' appearance along the margins of the oval and round windows and around the cochlea, indicating new bone formation.

Image

Fenestral otospongiosis CT scan.
MRI

M RI is less sensitive for these findings, though T2-weighted images may show a high intraosseous signal intensity in the cochlear form of otosclerosis. ${ }^{17}$

\section{Meniere's Disease}

M eniere's disease is a disorder of the inner ear that is also known as idiopathic endolymphatic hydrops.

The role of CT and MR studies in the evaluation of patients with Meniere's disease is to exclude other pathologic conditions that could masquerade as M eniere's disease clinically. ${ }^{18}$

\section{CT Scan}

CT scans should be normal. They are obtained to detect possible dehiscences of the semicircular canals, congenital abnormalities, widened cochlear and vestibular aqueducts, and subarachnoid hemorrhage. CT scans reveal dehiscent superior semicircular canals and/or widened cochlear and vestibular aqueducts.

\section{MRI}

On M RIs, the endolymphatic sac may or may not be visible, but the sacculus and basal turn of the cochlea are dilated. The cochlea resembles the planet Saturn and its ring.

Saturn part represents dilatation of the middle and apical turns of the cochlea and the ring represents dilatation of the sacculus and the basal turn of the cochlea.

Dilatation of the basal turn of the cochlea is seen as an area of high signal intensity or a ring around the middle and apical turns of the cochlea. ${ }^{19}$

Even though no imagine technique is specific enough to set the diagnosis of M eniere's disease alone, the recent use of 3D fluid-attenuated inversion recovery (3D-FLAIR) $M R I$ protocols in $3 T$ field strengths can delineate the perilymphatic and endolymphatic spaces of the inner ear after intratympanic injection of gadolinium DTPA (Gd-DTPA). Vestibular enhancement is observed first, followed by advance of the enhancement to the basal cochlear turn and semicircular canals and, finally, the apical turn of the cochlea. Twenty-four hours is the optimal interval between $\mathrm{Gd}$ administration and M R examination, when evaluating the whole labyrinthine system. In patients with endolymphatic hydrops, the perilymphatic space surrounding the endolymph is either small or cannot be visualized. ${ }^{20,21}$

Image

MRI protocols in a patient with Meniere's disease. High spatial resolution 3D-real inversion recovery (IR) image. 
By comparing the perilymphatic VR image (c) and total Iymphatic VR image (d), we can appreciate the degree of endolymphatic hydrops three-dimensionally. ${ }^{21}$

\section{Superior Semicircular Canal Dehiscence}

A syndrome of sound- and/or pressure-induced vertigo due to a dehiscence of bone overlaying the superior semicircular canal (SSC) has been described. Patients with this vestibular disturbance can report vertigo (an illusion of motion) and/ or oscillopsia (apparent motion of objects that are known to be stationary) evoked by loud noises (Tullio phenomenon). ${ }^{22}$

Oval and the round windows are the only two openings in the fluid-filled system of the inner ear. If there is a dehiscence of a semicircular canal and the creation, therefore, of a 'third' window, fluid movement within the semicircular canal can occur in response to sound vibration of the stapes.

\section{CT}

Thin section ( $0.6 \mathrm{~mm}$ collimation) multislice CT volume acquisition (to facilitate high-resolution multiplanar reformatting) is required to optimize sensitivity and specificity.

CT demonstration of a small defect in the bony wall of the superior semicircular canal.

\section{MRI}

T2-weighted and fast spin echo can show the clear contact between inner ear and brain fluid.

MRI may have as much as $96 \%$ sensitivity and $98 \%$ specificity for the identification of the syndrome.

M R I may shows the underlining cause of symptoms as being SCD, when performed for suspected intracranial lesions.

Image

Coronal image reformatted from transverse multidetector row CT images of a left temporal bone shows a dehiscence of the superior semicircular canal.

\section{CP Angle Tumors and other Pathologies of the IAM and CP Angle which may Present with Vertigo}

Internal Auditory Canal or Cerebellopontine Angle

- Neoplastic lesions

- Schwannoma (acoustic neuroma) meningioma

- A rachnoid cyst

- Epidermoid cyst

- Leptomeningeal neoplastic seeding lipoma

- Hemangioma

- Non-neoplastic lesions
- Sarcoidosis

- Meningitis

- Vascular loop

- Siderosis

- Intra-axial auditory pathways

- Ischemic lesions

- Neoplastic lesions

- Traumatic lesions

- Demyelinating lesions

Cerebellopontine angle masses (CPA): Only most common pathologies were included:

- Schwannoma (8th $\gg>$ 5th)

- Meningioma

- Epidermoid

\section{Epidermoid}

Epidermoid cysts or tumors, also known as primary cholesteatomas, are the third most frequent tumor of the CPA. ${ }^{23}$

Their growth is due to accumulation of keratin and cholesterol produced by desquamation of the squamous epithelium lining the mass.

These slow-growing tumors encase and surround nerves and arteries in the cisterns rather than displacing them.

\section{CT}

Epidermoid cysts appear hypoattenuating, almost isoattenuating to CSF, and have characteristic irregular, lobulated margins.

Slight marginal calcifications or enhancement after contrast material administration are rarely seen. ${ }^{24}$

MRI

Epidermoid cysts have slightly higher signal intensity than CSF on T1- and T2-weighted images, often with heterogeneous and marbled features (Fig. 3).

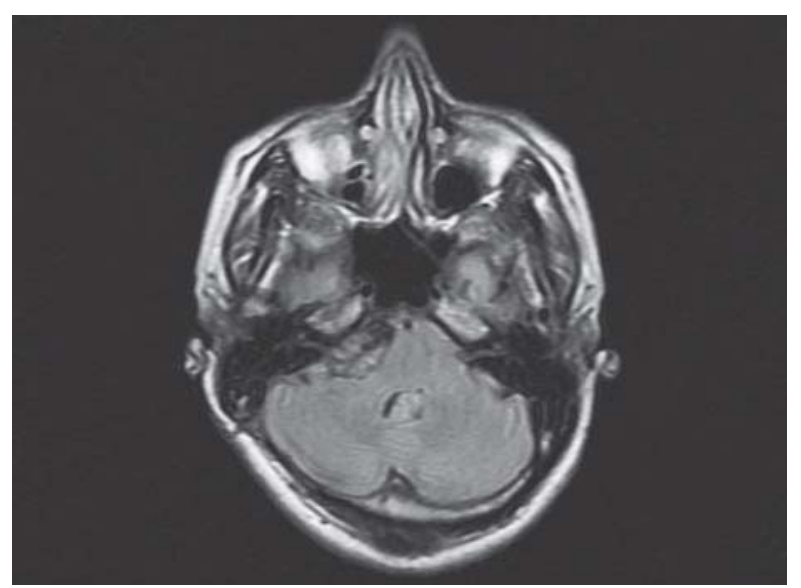

Fig. 3: Epidermoid flair axial 
Diffusion-weighted imaging is also well know $n$ to allow differentiation of epidermoid and arachnoid cysts. The apparent diffusion coefficient of an epidermoid cyst is significantly lower than that of an arachnoid cyst; therefore, epidermoid cysts have high signal intensity on diffusion weighted images, whereas arachnoid cysts, like CSF, have very low signal intensity. ${ }^{25}$

\section{Acoustic Schwannoma}

A coustic schwannomas are benign tumors, which usually arise from the intracanalicular segment of the vestibular portion of the the vestibulocochlear nerve (CN VIII), near the transition point between glial and Schwann cells (O bersteiner-Redlich zone). ${ }^{26}$

In over $90 \%$ of cases, these tumors arise from the inferior division of the vestibular nerve.

M ost vestibular schwannomas have an intracanalicular component, and often result in widening of the porus acousticus resulting in the trumpeted IAM sign, which is present in up to $90 \%$ of cases. ${ }^{27}$

In a minority of cases, they are purely extracanalicular, only abutting the porus acusticus.

At times, these tumors will grow laterally through the cochlear or vestibule into the middle ear.

Rarely, they are small and confined to the labyrinth.

Small tumors tend to be solid, whereas cystic degeneration seen commonly in larger tumors. Hemorrhagic areas may also be seen.

Calcification is typically not present.

\section{CT}

Density of these tumors on noncontrast imaging is variable, and often they are hard to see, especially on account of beam hardening and streak artefact form the adjacent petrous temporal bone. It may show erosion and widening of the internal acoustic meatus.

Contrast enhancement is present, but can be underwhelming, especially in larger lesions with cystic components.
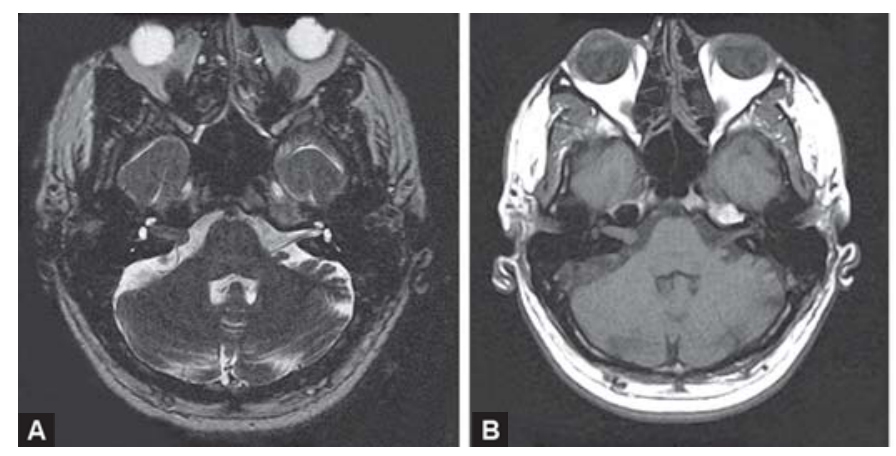

Figs 4A to D: (A) T2W axial image right acoustic schwannoma, (B) T1W axial image, (C) T1W postcontrast axial image,

(D) another large right acoustic schwannoma postcontrast T1W1
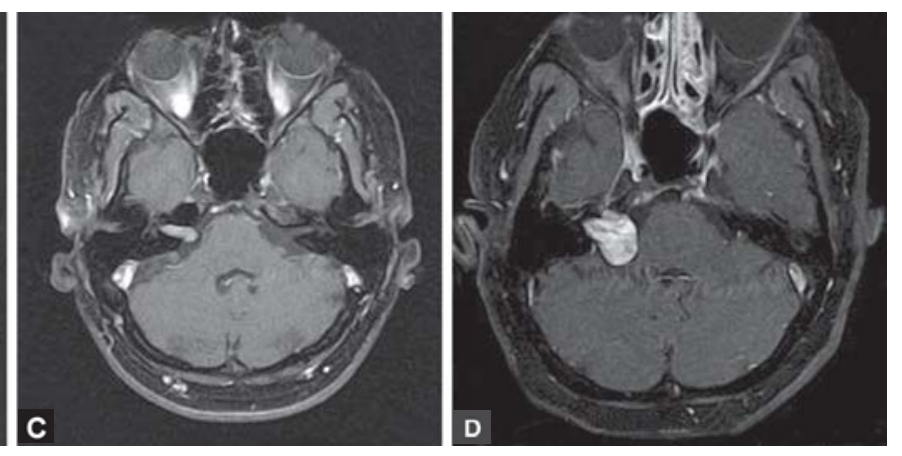

MRI

On T IW I slightly hypointense to isointense to adjacent brain parenchyma (Figs $4 \mathrm{~A}$ and $\mathrm{B}$ ). ${ }^{26}$

- It may contain hypointense cystic areas.

- On T2WI heterogeneously hyperintense to adjacent brain. ${ }^{27}$

- It may have cystic areas showing fluid intensity.

- It may have associated peritumoral arachnoid cysts. ${ }^{28}$

- Postcontrast enhancement is vivid, but heterogeneous in larger tumors (Figs 4C and D).

\section{Meningioma}

A meningioma is the most common type of extra-axial neoplasm and accounts for 14 to $20 \%$ of intracranial neoplasms. ${ }^{29}$ It is a nonglial neoplasm that originates from the arachnoid cap cells of the meninges.

Five to $10 \%$ juxtasellar, i.e. CPA masses.

\section{Plain Film Skull}

- Enlarged meningeal artery grooves

- Hyperostosis or lytic regions

- Calcification

CT

- Sixty percent slightly hyperdense to normal brain

- Twenty to $30 \%$ have some calcification ${ }^{30}$

- Seventy-two percent brightly and homogenously contrast enhance, less frequent in malignant or cystic variants hyperostosis is typical in meningiomas and need to distinguish reactive hyperostosis from skull vault invasion.

\section{MRI}

- On T2WI hypo- to iso- to hyperintense to gray matter (the intensity varies according to tumoral cellularity: Higher the cellularity lower the signal intensity on both $\mathrm{TI}$ and $\mathrm{T} 2 \mathrm{WI}$ ) (Fig. 5A).
- On TIWI hypo- to isointense compared to gray matter. 

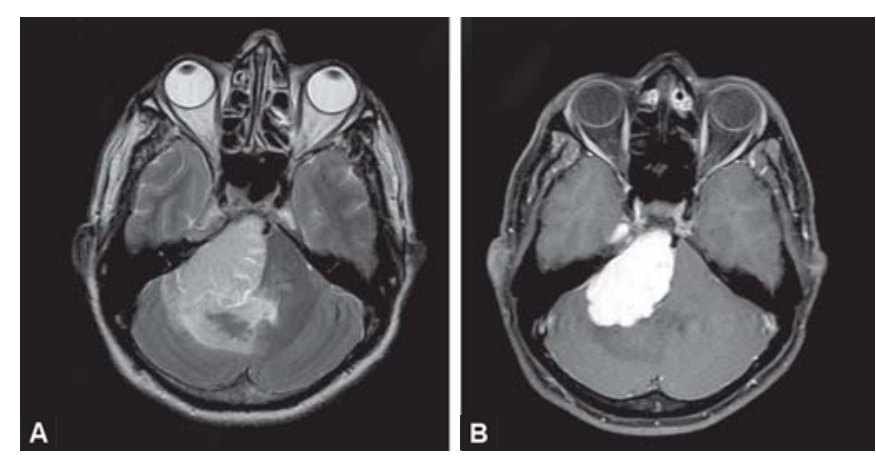

Figs 5A and B: (A) T2W1 axial images: Right CP angle meningioma, (B) T1W1 postcontrast image: Right CP angle meningioma

- Postcontrast- the tumor shows intense homogenous enhancement (Fig. 5B).

- DW I atypical and mal ignant subtypes may show greater than expected restricted diffusion.

\section{Specific Signs}

- CSF cleft sign (the cleft was regarded as representing a thin rim of CSF between tumor and brain parenchyma).

- Dural tail (as a result of thickening of the dura). ${ }^{31}$

\section{Angiography}

- 'M other-in-law sign': 'Comes early, stays late, very dense' - tumor blush

Meningiomas have dual blood supply from both pial vessels, i.e. ICA supplies periphery of the tumor and meningeal vessels, i.e. ECA supplies core of the tumor.

They typically show spoke-wheel appearance and densevenous filling.

\section{REFERENCES}

1. Layton KF, Lane JI, W itte RJ, Colin LW, Driscoll W eber PC. Radiology for vertigo and disequilibrium. A practical guide to diagnosis and management thieme 2008:15.

2. Drachman DA. A 69-year-old man with chronic dizziness [published correction appears in J A M A 1999;281:899]. JA M A 1998;280:2111-18.

3. Hanley K, O'Dowd T, Considine N. A systematic review of vertigo in primary care. BrJ G en Pract 2001;51:666-71.

4. K roenkeK, L ucas CA, R osenberg M L, Scherokman B, Herbers JE Jr, W ehrle PA, et al. Causes of persistent dizziness. A prospective study of 100 patients in ambulatory care. A nn Intern Med 1992;117:898-904.

5. Derebery MJ. The diagnosis and treatment of dizziness. M ed Clin N orth A m 1999;83:163-77.

6. Brandt T, B ronstein A M . Cervical vertigo. J N eurol N eurosurg Psychiatry 2001;71:8-12.

7. Tusa RJ, Herdman SJ. Diagnosis and treatment of the dizzy patient. Hospital Physician 1997;33:22-37.

8. Solomon D. Distinguishing and treating causes of central vertigo. Otolaryngol Clin North A m 2000;33:579-601.
9. Wippold FJ II, Turski PA . A m J Neuroradiol. Sep 2009;30:162325. www.ajnr.org.

10. Schuknecht HF. Pathology of ear (2nd ed). Philadel phia: Lea and Febiger 1993.

11. Swartz JD, Harnsberger HR. Imaging of the temporal bone. Thieme 1998.

12. $M$ afee $M F, V$ alvassori GE, B ecker $M$. Imaging of the head and neck. Thieme, 2004.

13. Beaumont GD. Radiology and the management of chronic suppurative otitis media. A ustalas Radiol 1980;24:238-45.

14. Som PM, Curtin HD. Head and neck imaging (4th ed). Mosby, 2002;1207-08.

15. Som PM , Curtin HD. Head and neck imaging (4th ed). M osby, 2002;1211.

16. Gristwood RE, V enables W N . Otosclerosis and chronic tinnitus. Ann Otol Rhinol Laryngol 2003;112:398-403.

17. Remley KB, Coit WE, Harnsberger HR, et al. Pulsatile tinnitus and the vascular tympanic membrane: $\mathrm{CT}, \mathrm{M} \mathrm{R}$, and angiographic findings. Radiology 1990;174:383-88.

18. N eissmann JL. Imaging of $\mathrm{M}$ eniere's disease. Otolaryngol Clin North A m 1997 Dec; 30(6):1105-16.

19. Suchatoc, et al. $M R$ imaging in the patient with $M$ énière disease. AJR 1993;161:1263-64.

20. N akashima T, N aganawa S, Sugiura M, Teranishi M, Sone M, Hayashi $\mathrm{H}$, et al. V isualization of endolymphatic hydrops in patients with Meniere's disease. Laryngoscope 2007;117: 415-20.

21. Naganawa S, N akashima T. Cutting edge of inner ear M RI. A cta Otolaryngol Suppl 2009;129:15-21.

22. Clifford JB, W eg N, M inor LB, Zinreich SJ. CT evaluation of bone dehiscence of the superior semicircular canal as a cause of sound- and/or pressure-induced vertigo. Radiology 2003 Feb 226(2):337-38.

23. Jeanbourquin D, Cordoliani Y S, Derosier C, Cosnard G. Cholestéatomes de la fosse cérébrale postérieure: sept observations et revue dela littérature. J Radiol 1993;74:555-61.

24. Smirniotopoulos JG, Chiechi MV. Teratomas, dermoids, and epidermoids of the head and neck. RadioG raphics 1995; 15:1437-55.

25. Bonneville F, Sarrazin JL, M arsot-Dupuch K, Iffenecker C, Cordoliani Y S, Doyon D. Unusual lesions of the cerebellorpontine angle: A segmental approach. RadioGraphics 2001;21:419-38.

26. M ulkens TH, Parizel PM , M artin JJ, et al. A coustic schwannoma: MR findings in 84 tumors. AJR A m J Roentgenol 1993;160 (2):395-98.

27. M orantz RA, Walsh JW. B rain tumors. A comprehensive text. Informa HealthCare 1994.

28. Tali ET, Y uh WT, N guyen HD, et al. Cystic acoustic schwannomas: MR characteristics. A J NR A m J Neuroradiol 14(5):1241-47.

29. Filippi CG, Edgar MA, Uluğ $A M$, et al. Appearance of meningiomas on diffusion-weighted images: Correlating diffusion constants with histopathologic findings. A JNR A m J Neuroradiol 2001;22(1):65-72.

30. Greenberg H, Chandler WF, Sandler HM . B rain tumors. Oxford University Press, USA 1999.

31. Wallace EW. The dural tail sign. Radiology 2004;233(1): 56-57. 


\section{ABOUT THE AUTHORS}

\section{Deepak Patkar}

Head, D epartment of PET CT and M RI, Dr B alabhai N anavati H ospital M umbai, M aharashtra, India

CorrespondenceAddress: 10, Laxmi Mahal, Bomanji Petit Street Warden Road, Near Parsi General Hospital, M umbai, M aharashtra India, Phone: 2223890636, e-mail: drdppatkar@gmail.com

\section{Girish Yevankar}

Consultant Radiologist, L otus I maging Clinics, K harghar and Panvel M umbai, M aharashtra, India

\section{Rashmi Parikh}

Radiology Resident, Nanavati Hospital, M umbai, M aharashtra, India 